\title{
Theoretical Impact of Replacing Whole Cow's Milk by Young-Child Formula on Nutrient Intakes of UK Young Children: Results of a Simulation Study
}

\author{
Simone R.B.M. Eussen ${ }^{a}$ Josephine Pean ${ }^{b}$ Leanne Olivier ${ }^{a, c}$ Fabien Delaere ${ }^{b}$ \\ Anne Lluch ${ }^{\text {b }}$ \\ ${ }^{a}$ Nutricia Research, Utrecht, The Netherlands; ${ }^{b}$ Danone Nutricia Research, Centre Daniel Carasso, Palaiseau, France; \\ 'Danone Nutriticia Early Life Nutrition, Trowbridge, UK
}

\section{Key Words}

Young-child formula . United Kingdom .

Nutritional adequacy $\cdot$ Cow's milk $\cdot$ Simulation

\begin{abstract}
Background: Research into the role of young-child formulae (YCF) in a child's diet is limited and there is no consensual recommendation on its use. We evaluated the theoretical nutritional impact of replacing the existing practice of consuming cow's milk by YCF. Methods: From the UK Diet and Nutrition Survey of Infants and Young Children, whole cow's milk consumers, aged $12-18$ months $(n=591)$ were selected for simulation scenarios. In Scenario 1, we tested the replacement of all whole cow's milk ( $434 \pm 187 \mathrm{ml} /$ day) by a matching volume of YCF, and in Scenario 2, all whole cow's milk was replaced by the on-pack recommended daily intake of $300 \mathrm{ml}$. Nutrient intakes before and after simulation scenarios were compared and evaluated against nutrient recommendations. Results: Intakes of protein and saturated fatty acids were significantly decreased, whereas essential fatty acid intakes were increased. The prevalence of nutrient inadequacy before simulation was $95.2 \%$ for vitamin D and $53.8 \%$ for iron. After simulation, inadequacy decreased to $4.9 \%$ (Scenario 1) and 0\% (Scenario 2) for vitamin D and to $2.7 \%$ (Scenario 1) and 1.1\% (Scenario 2) for iron. Conclusions: Re-
\end{abstract}

placement of habitual cow's milk intake by a matching volume or $300 \mathrm{ml}$ of YCF may lead to nutritional intakes more in line with recommendations in young children.

(c) 2015 The Author(s)

Published by S. Karger AG, Basel

\section{Introduction}

Young childhood (1-3 years of age) is a period of rapid growth and development. Between 1 and 3 years of age, young children gain about $25 \%$ in height and $50 \%$ in weight [1]. Due to this rapid growth and development, young children have increased nutritional needs. For example, young children need approximately 5.5 times as much iron per kilogram of bodyweight and 7 times as much vitamin D compared to adults [2]. At the same time, young children can only eat relatively small amounts of foods because of their limited gastric capacity. In order to fulfil their requirements, young children should therefore eat a well-balanced, nutrient-dense diet. Neophobia and picky eating are common during this age [3], putting the young child at a higher risk of nutrient inadequacies and/or excesses.

S.R.B.M.E. and J.P. contributed equally to this work.

\begin{tabular}{|c|c|c|}
\hline \multirow{3}{*}{$\begin{array}{l}\text { KARGER 125/s } \\
\text { E-Mail karger@karger.com } \\
\text { www.karger.com/anm }\end{array}$} & (c) 2015 The Author(s) & Karger \\
\hline & $\begin{array}{l}\text { Published by S. Karger AG, Basel } \\
0250-6807 / 15 / 0674-0247 \$ 39.50 / 0\end{array}$ & Open access \\
\hline & $\begin{array}{l}\text { This article is licensed under the Creativ } \\
\text { NonCommercial-NoDerivatives } 4.0 \text { Inter } \\
\text { NC-ND) (http://wwww.karger.com/Servi } \\
\text { Usage and distribution for commercial pu } \\
\text { tribution of modified material requires wr }\end{array}$ & $\begin{array}{l}\text { Commons Attribution- } \\
\text { ational License (CC BY- } \\
\text { es/OpenAccessLicense). } \\
\text { poses as well as any dis- } \\
\text { ten permission. }\end{array}$ \\
\hline
\end{tabular}

Simone R.B.M. Eussen

Nutricia Research, Developmental Physiology and Nutrition Uppsalalaan 12

3584 CT Utrecht (The Netherlands)

E-Mail Simone.Eussen@danone.com 
The UK Diet and Nutrition Survey of Infants and Young Children (DNSIYC, 2011) showed that the average intakes of vitamin D and iron of children aged 4-18 months were below the reference nutrient intake (RNI). Ten to $14 \%$ of children had iron intakes below the lower reference nutrient intake (LRNI), that is, the quantity sufficient for only $2.5 \%$ of the population [4]. Similar results are observed in other European countries, showing inadequate intakes of iron and vitamin $\mathrm{D}$ in young children, as well as of alpha-linolenic acid, docosahexaenoic acid and iodine (in some European countries) [5]. On the other hand, nutrient excesses are also often observed in childhood. The DNSIYC reported that energy intake of $75 \%$ of the children exceeded the requirements and average protein intakes were more than twice the RNI, that is, 38 vs. $14.5 \mathrm{~g} /$ day representing $16 \%$ of total energy intake (\%EI) $[4,6]$. In a 2013 opinion on nutritional intakes of infants and young children, the European Food Safety Authority (EFSA) Panel on Dietetic Products, Nutrition and Allergies (NDA) considered that a high intake of protein (up to $20 \% \mathrm{EI}$ ) is not at a level that is of concern [5]. Nevertheless, in a subsequent opinion on the composition of infant and follow-on formulae, the EFSA NDA Panel proposes that the maximum protein content for infant and follow-on formulae should be reduced from 3.0 and $3.5 \mathrm{~g} / 100 \mathrm{kcal}$, respectively to $2.5 \mathrm{~g} / 100 \mathrm{kcal}$, based on the lack of evidence of a physiological need for such high protein intakes and because of the fact that current intakes are well above requirements [7]. In addition, several authors have suggested an association between a protein-driven rapid weight gain in infancy and an increased risk of obesity in later life [8], with a potential critical threshold of 15\%EI obtained from protein [9-11]. In addition to energy and protein, also salt (sodium) intakes of many young children are high and may be related to elevated blood pressure, a risk factor for cardiovascular and renal diseases [5].

Young-child formulae (YCF) are milk-based drinks intended for children from 1 year and usually up to 3 years of age in Europe [5]. They are fortified with several nutrients that can be lacking in the diets of young children, including iron, vitamin D and essential fatty acids and contain lower protein, saturated fat and sodium compared to cow's milk, the main dairy-based drink in the diets of young children in most European countries. Research into the role of YCF in a young child's diet is limited and there is no consensual recommendation on the use of YCF. According to the EFSA NDA Panel [5], YCF constitute one of the means to decrease the risk of inadequate intakes of specific nutrients in the diets of young children, but the Panel stressed that they do not recognize a unique role for YCF with respect to the provision of these nutrients. On the other hand, some studies have investigated the excessive nutrient intakes that can result from the consumption of fortified foods. Fortification of commonly consumed foods with some micronutrients, for example, vitamin A, could result in a high percentage of young children having intakes above the tolerable upper intake level (UL) [12].

The objective of this study was to evaluate the theoretical nutritional impact of replacing the existing practice of cow's milk intake by YCF, in order to identify the nutritional benefits and risks potentially linked to the consumption of this type of formula. Additionally, we assessed whether the on-pack recommended intake level of $300 \mathrm{ml} /$ day is appropriate in terms of adequate nutrient intakes.

\section{Methods}

\section{Study Sample}

Analyses were performed using data from the UK DNSIYC, 2011. The design, methodology and results of the DNSIYC have already been described in detail [4]. In brief, a randomly selected sample of 2,683 infants and young children aged 4-18 months living in private households across the United Kingdom was included. Parents were asked to describe everything their child was offered over a 4-day period in household measures and to record left over foods/drinks. From the types and quantities of foods consumed, estimates of nutrient intakes were derived using the Department of Health's Nutrient Databank [13]. We selected only children aged 12 months onwards, as this is the target group of YCF $(n=1,275)$. Moreover, in order to be as accurate as possible, we restricted our sample to children with a milk consumption made up entirely of whole cow's milk, leading to a final sample size of 591 children ( $46 \%$ of target group) in the study. This choice was made because whole cow's milk is the type of milk recommended by the British Nutrition Foundation and the UK Infant and Toddler Forum $[14,15]$.

\section{Simulation Replacement Scenarios}

For the objectives of this study, 2 replacement scenarios were defined using deterministic simulation analyses. In Scenario 1, individual intake of cow's milk was simulated to be replaced by YCF at a matching volume (mean intake $434 \pm 187 \mathrm{ml} /$ day). In Scenario 2, individual cow's milk intake was, independently of a child's original consumption level, replaced by $300 \mathrm{ml}$ of YCF, a similar intake level as suggested by the British Nutrition Foundation [16]. This level of intake is also the on-pack recommended amount. Table 1 presents the average composition of whole cow's milk compared to the composition of the YCF used for this study (Aptamil Growing Up milk 1-2 years) and the average composition (p5, median and p95) of YCF on the European market [5]. The YCF was selected because it is the most commonly consumed YCF by children aged 12-18 months in the United Kingdom. 
Table 1. Nutritional composition of whole cow's milk compared with the young-child formula used for simulation scenarios and the average composition of young-child formulae on the European market [5]

\begin{tabular}{|c|c|c|c|c|c|}
\hline & \multirow{2}{*}{$\begin{array}{l}\text { Cow's milk, } \\
\text { whole, } \\
\text { per } 100 \mathrm{~g}\end{array}$} & \multirow{2}{*}{$\begin{array}{l}\text { Young-child } \\
\text { formula, } \\
\text { per } 100 \mathrm{~g}\end{array}$} & \multicolumn{3}{|c|}{$\begin{array}{l}\text { Average composition of young-child } \\
\text { formulae, per } 100 \mathrm{~g}^{1}\end{array}$} \\
\hline & & & p5 & median & p95 \\
\hline Energy, kcal & 67 & 65 & 50 & 67 & 81 \\
\hline Protein, $g$ & 3.3 & 1.5 & 1.4 & 1.7 & 2.4 \\
\hline Carbohydrates, g & 4.9 & 8.5 & 7.4 & 8.4 & 9.6 \\
\hline NMES, $g$ & 0 & 0.5 & & & \\
\hline Lactose, $g$ & 4.9 & 6.2 & & & \\
\hline Fat, $g$ & 3.9 & 2.6 & 2.3 & 2.9 & 3.2 \\
\hline SFA, $g$ & 2.4 & 0.6 & 0.3 & 0.9 & 1.4 \\
\hline Cis n3 fatty acids, mg & 20 & 64 & & & \\
\hline Cis $\mathrm{n} 6$ fatty acids, $\mathrm{mg}$ & 70 & 364 & & & \\
\hline Fibre, $g$ & 0 & 0.8 & & & \\
\hline Sodium, mg & 41 & 26 & 19 & 27 & 38 \\
\hline Calcium, mg & 117 & 120 & 63 & 85 & 147 \\
\hline Iron, mg & 0 & 1.2 & 0.9 & 1.2 & 1.6 \\
\hline Iodine, $\mu \mathrm{g}$ & 38 & 20 & 8.2 & 14 & 23 \\
\hline Zinc, mg & 0.3 & 0.9 & 0.5 & 0.8 & 1.3 \\
\hline Vitamin $A, \mu g$ RE & 29 & 68 & 52 & 68 & 95 \\
\hline Retinol, $\mu \mathrm{g}$ & 27 & 68 & & & \\
\hline Vitamin C, mg & 2 & 15 & 5.8 & 11 & 16 \\
\hline Vitamin $\mathrm{D}, \mu \mathrm{g}$ & 0 & 3.1 & 0.9 & 1.4 & 2.2 \\
\hline
\end{tabular}

\section{Data Analyses}

All analyses were performed using the software Creme Food (Creme Global Ltd., Dublin, Ireland). Nutritional intakes (mean \pm $\mathrm{SD}$ ) before and after simulation were compared using a paired Wilcoxon test, and evaluated against different nutrient recommendations for young children. For micronutrients, we used the reference value as described in the UK nutrient recommendations for children aged 12-36 months [17]. For most macronutrients, no UK nutritional recommendation for children aged less than 5 years has been developed. Therefore, we used the reference value of the EFSA NDA Panel for total protein, total carbohydrates, fibre and total fat [18-20]. Nordic recommendations [2] were used as a complement for essential fatty acids as reference values for these fatty acids were not given in the earlier mentioned recommendations. Because the Nordic recommendations for children aged 12-23 months and for adults and children from 2 years of age did not differ for added sugars and saturated fatty acids (SFA) [2], we used the reference value as described in the UK nutritional recommendations for children older than 5 years for non-milk extrinsic sugars (NMES) and SFA (see online suppl. table for the different recommendations; for all online suppl. material, see www.karger. com/doi/10.1159/000440682).

Percentages of children having intakes below the LRNI, the estimated average requirement (EAR) and the RNI were calculated, as well as percentages of children with intakes above the UL [17]. In line with the approach of the EURopean micronutrient RECommendations Aligned (EURRECA) Network of Excellence [21], micronutrient intakes below the EAR were perceived as in- adequate. Results were considered statistically significant when $p$ values for the paired Wilcoxon test between before and after simulation were $<0.001$.

\section{Results}

\section{Population Characteristics}

The mean age of children in the study was $14.6 \pm 1.5$ months and $52 \%$ of the sample constituted boys. The children consumed daily on average $434 \pm 187 \mathrm{ml}$ of cow's milk, with $78.2 \%$ of the children consuming more than the recommended $300 \mathrm{ml}$ per day. The distribution of cow's milk consumption before simulation can be found in the online supplementary figure.

\section{Energy Intakes}

Mean energy intakes did not significantly change after replacing cow's milk intake by YCF at matching volume (Scenario 1). Reducing the average intake level $(434 \pm 187 \mathrm{ml} /$ day $)$ with the on-pack recommended amount of $300 \mathrm{ml}$, decreased energy intake from 4.1 to 3.7 $\mathrm{MJ} /$ day (i.e. about $-100 \mathrm{kcal} /$ day). Because Scenario 1 is the most realistic scenario, as no energy compensation is 
Fig. 1. Mean macronutrients intakes in per cent of energy intake $( \pm \mathrm{SD})$ before and after simulation scenarios (Scenario 1: replacement of whole cow's milk by YCF at matching volume; Scenario 2: replacement of whole cow's milk by $300 \mathrm{ml} /$ day YCF). ${ }^{* * *} \mathrm{p}<0.001$ compared to baseline (paired Wilcoxon test).

Fig. 2. Mean micronutrients intakes $( \pm$ SEM) before and after simulation scenarios (Scenario 1: replacement of whole cow's milk by YCF at matching volume (MV); Scenario 2: replacement of whole cow's milk by $300 \mathrm{ml} /$ day YCF). a Calcium intakes, b vitamin D intakes, $\mathbf{c}$ iron intakes, $\mathbf{d}$ zinc intakes. ${ }^{* * *} \mathrm{p}<0.001$ compared to baseline (paired Wilcoxon test).

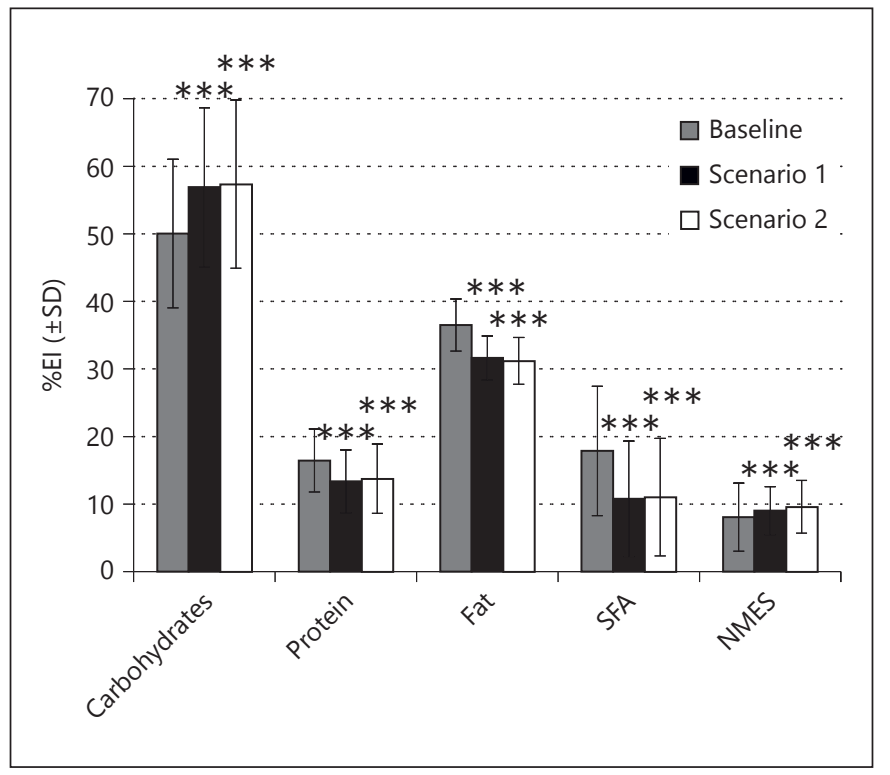

1
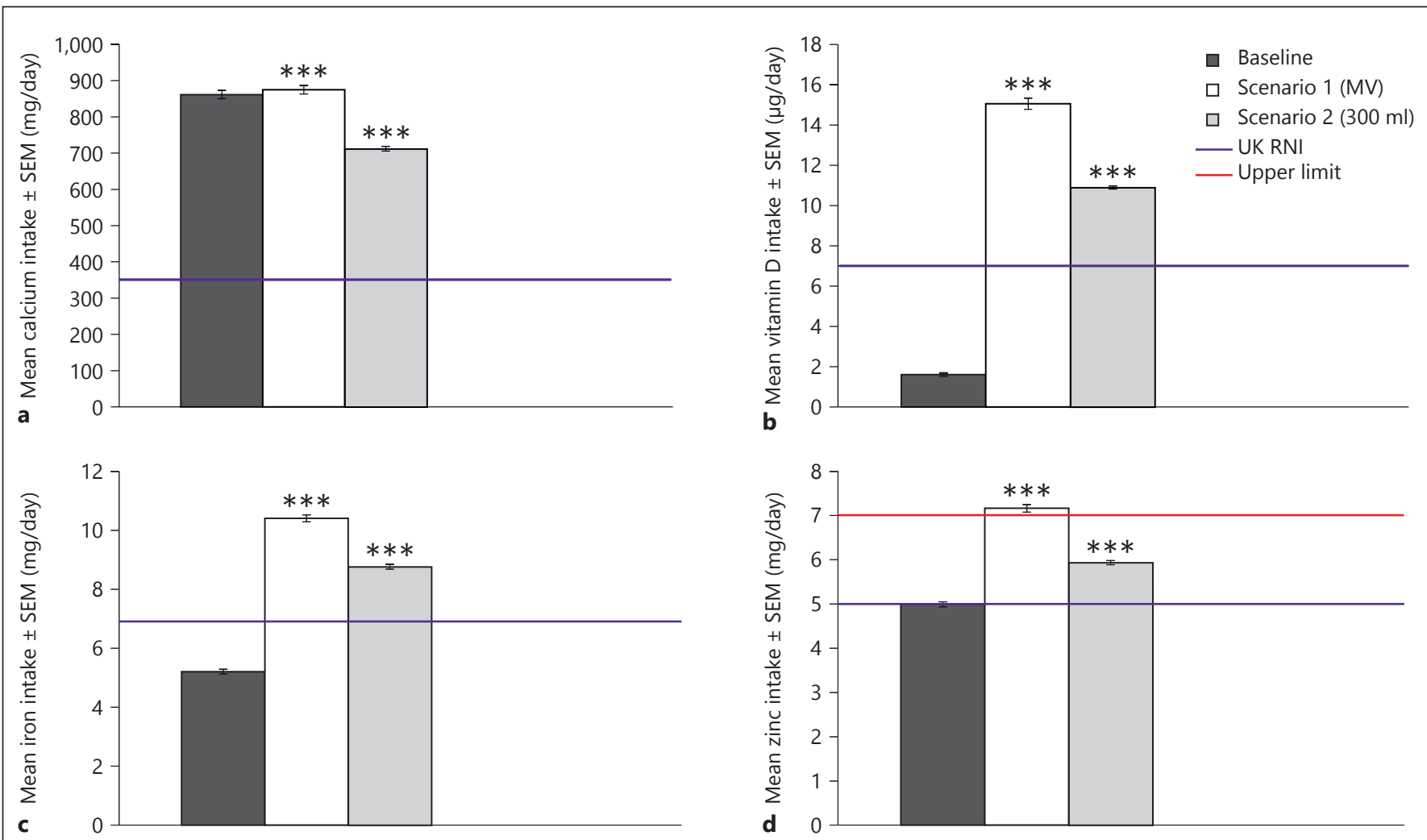

needed and results for macro- and micronutrients were similar for Scenario 1 and Scenario 2, hereafter, a focus will be made on Scenario 1. Complete results for Scenario 1 and Scenario 2 can be found in figures 1 and 2, and tables 2 and 3.

\section{Macronutrient Intakes}

Protein intakes were significantly decreased after replacement of cow's milk by YCF, that is, from $16.5 \% \mathrm{EI}$ before simulation to $13.4 \% \mathrm{EI}$ in Scenario 1 (table 2; fig. 1). None of the subjects had protein intakes below the 
Table 2. Mean (SD) intakes of macro- and micronutrients and \%EI of macronutrients before and after simulation scenarios (Scenario 1: replacement of whole cow's milk by YCF at matching volume; Scenario 2: replacement of whole cow's milk by $300 \mathrm{ml} / \mathrm{day}$ YCF)

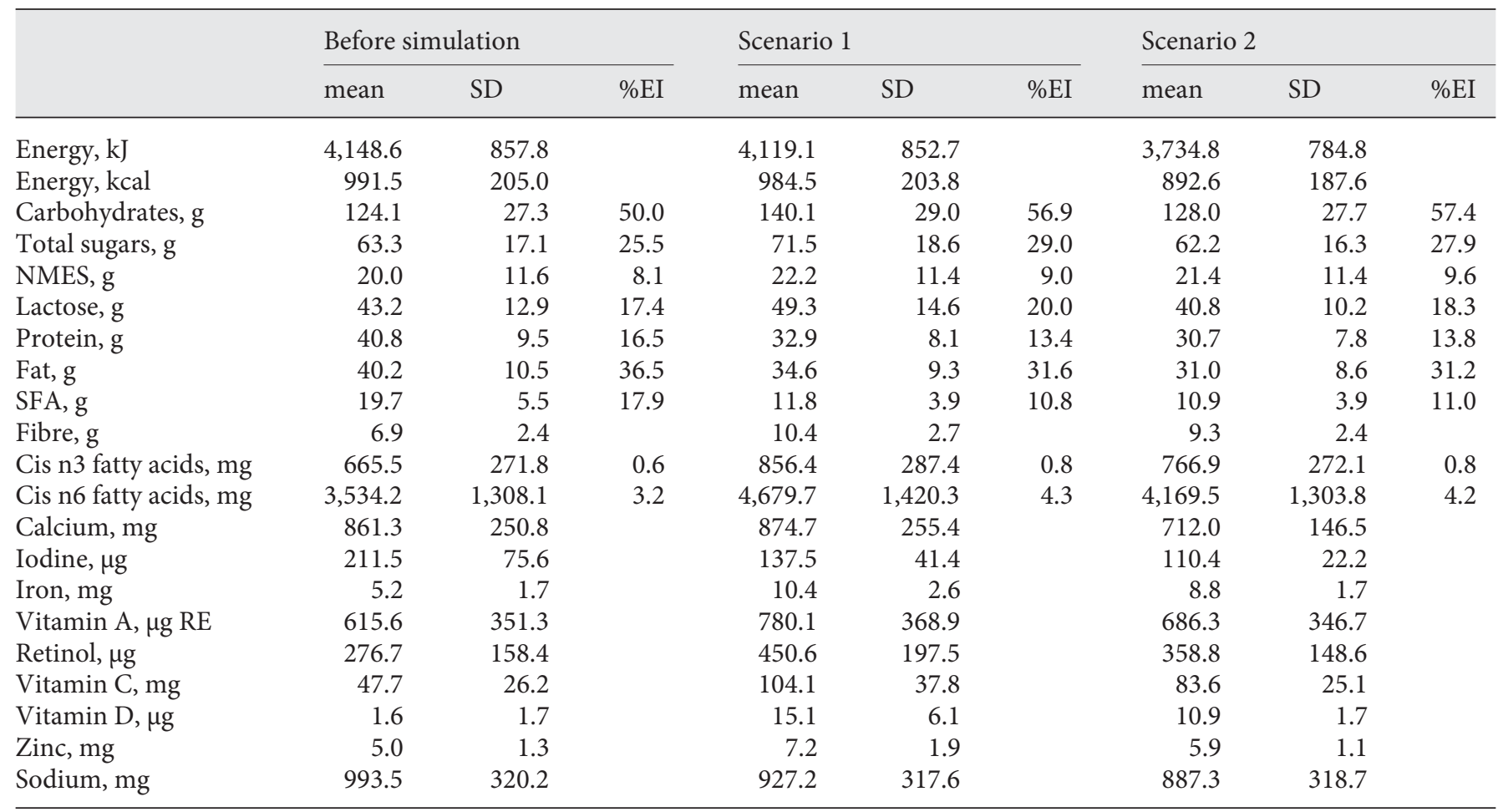

Table 3. Compliance with micronutrient recommendations before and after simulation scenarios (Scenario 1: replacement of whole cow's milk by YCF at matching volume; Scenario 2: replacement of whole cow's milk by $300 \mathrm{ml} / \mathrm{day}$ YCF)

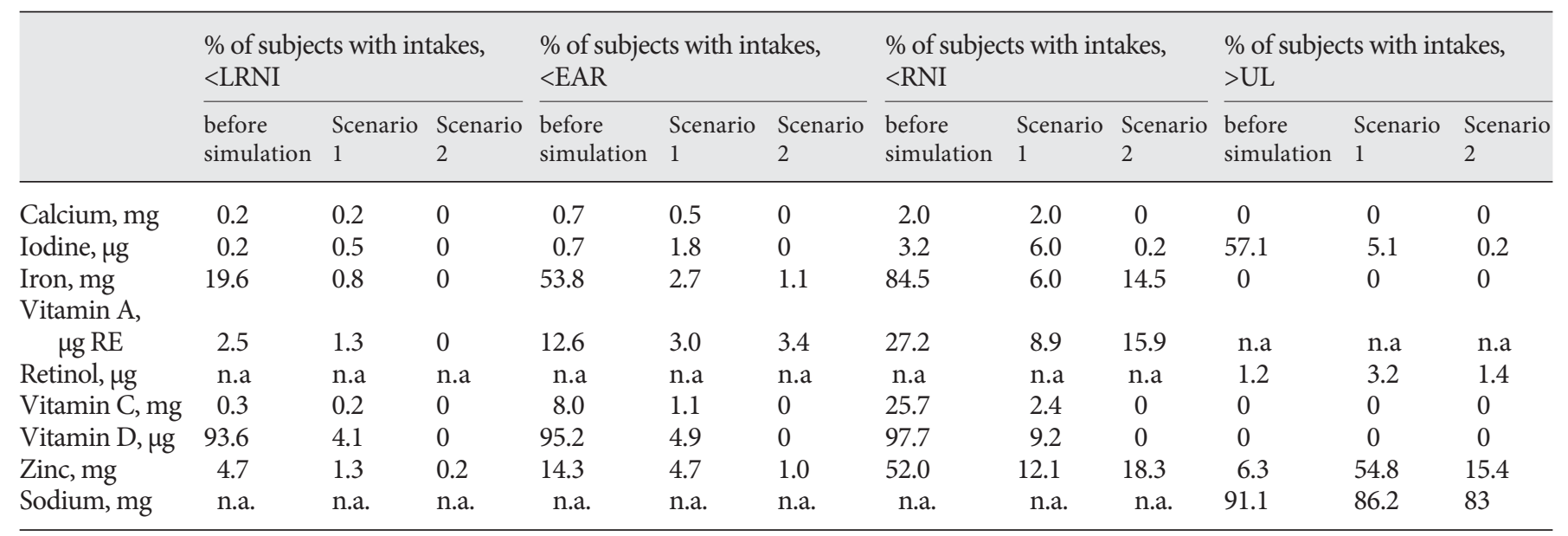

minimum requirement of $4.5 \%$ EI [20] before or after simulation, whereas 78.3 and $17.3 \%$ of the subjects had protein intakes above the UL of 15\%EI suggested by several authors [9-11] before and after simulation, respectively.

Simulating Replacement of Cow's Milk by YCF
Total and saturated fat intakes were also significantly decreased after simulating the replacement of cow's milk by YCF consumption. The mean total fat intake decreased from 36.5 to $31.6 \% \mathrm{EI}$ and intake of SFA decreased from 17.9 to $10.8 \% \mathrm{EI}$ after simulation. A total of $1.7 \%$ of sub- 
jects had intakes compliant to the UL of $11 \%$ EI for SFA intake [17] before simulation, and this increased to $59.4 \%$ after simulation. Essential fatty acid intakes were significantly increased after simulation, with Cis $\mathrm{n} 3$ fatty acids increasing from 0.6 to $0.8 \% \mathrm{EI}$ and Cis n6 fatty acids increasing from 3.2 to $4.3 \% \mathrm{EI}$ after simulation. The percentage of subjects with Cis $\mathrm{n} 6$ fatty acid intake above the minimum requirement of 4\%EI [2] increased from $15.7 \%$ before simulation to $59.2 \%$ after simulation.

Mean intakes of total sugars were significantly increased after replacement of cow's milk by YCF, that is, from $63.3 \mathrm{~g} /$ day $(25.5 \% \mathrm{EI})$ to $71.5 \mathrm{~g} /$ day $(29.0 \% \mathrm{EI}$, $+12.9 \%)$. This increase was mainly due to an increase in lactose ( $6 \mathrm{~g} /$ day, $73 \%$ of the increase). Also mean fibre intakes were significantly increased from $6.9 \mathrm{~g} /$ day before simulation to $10.4 \mathrm{~g} /$ day after simulation. A total of 9.3 and $52.3 \%$ of subjects had adequate daily intakes of fibre (intakes $>10 \mathrm{~g} /$ day as recommended by the EFSA NDA Panel [19]) before and after simulation, respectively.

\section{Micronutrient Intakes}

Mean intakes of iron, vitamin A, vitamin C, vitamin D and zinc were significantly increased after simulating the replacement of cow's milk by YCF consumption (table 2). The percentage of subjects having inadequate intakes, that is, an intake below the UK EAR, decreased from 53.8 to $2.7 \%$ for iron, from 12.6 to $3.0 \%$ for vitamin $\mathrm{A}$, from 8.0 to $1.1 \%$ for vitamin $\mathrm{C}$, from 95.2 to $4.9 \%$ for vitamin $\mathrm{D}$ and from 14.3 to $4.7 \%$ for zinc (table 3 ). For iron, vitamin $\mathrm{C}$ and vitamin $\mathrm{D}$, none of the children, either before or after simulation, had intakes above the UL. For preformed vitamin A (retinol), the percentage of subjects with intakes above the UL of $800 \mu \mathrm{g} /$ day [22] slightly increased from $1.2 \%$ before simulation to $3.2 \%$ after simulation. For zinc, the UL of $7 \mathrm{mg} /$ day [22] was exceeded by $6.3 \%$ of the subjects before simulation and $54.8 \%$ in Scenario 1.

Mean calcium intakes were similar before and after simulation with about $0.5 \%$ of children having an inadequate intake.

Mean iodine intakes were significantly decreased after replacement of cow's milk by YCF, that is, from $211 \mu \mathrm{g} /$ day at baseline to $137 \mu \mathrm{g} /$ day in Scenario 1 ( $-35 \%$; table 2). A total of $0.7 \%$ of subjects had inadequate iodine intake before simulation, compared to $1.8 \%$ after simulation. The UL of iodine of $200 \mu \mathrm{g} / \mathrm{day}$ [22] was exceeded by $57.1 \%$ before simulation, compared to $5.1 \%$ in Scenario 1.

Sodium intakes were slightly, but statistically significantly, decreased after simulating the replacement of cow's milk by YCF. Mean intakes were decreased from 993.5 to $927.2 \mathrm{mg}$ /day in Scenario $1(-6.4 \%)$. The UL of salt is set at $1.5 \mathrm{~g} /$ day, which corresponds to $600 \mathrm{mg}$ of sodium [23]. Before simulation, $91.1 \%$ of subjects exceeded this UL compared to $86.2 \%$ after simulation (table 3 ).

\section{Discussion}

The present simulation study showed that replacement of whole cow's milk by YCF, either at matching volume (mean $434 \mathrm{ml} /$ day, Scenario 1) or at the on-pack recommended amount of $300 \mathrm{ml}$ (Scenario 2), brought nutrient intakes of young children more in line with the recommendations.

A majority of UK children are given cow's milk as their main dairy-based drink from the age of 12 months onwards [4]. Two recently conducted observational studies compared the nutritional intakes of young children (1-2 years old) consuming YCF with those consuming cow's milk (skimmed, semi-skimmed or whole) [24, 25]. Both studies showed that a relatively high proportion of cow's milk consumers had inadequate intakes of iron and vita$\min \mathrm{D}$, and in one of the studies vitamin $\mathrm{C}$, linoleic acid and alpha-linoleic acid also [25]. The use of YCF was significantly associated with a reduced risk of insufficiencies in these nutrients. Moreover, YCF consumers had protein and SFA intakes more in line with the recommendations.

Our simulation scenarios suggest more specifically that the consumption of YCF instead of whole cow's milk may lead to improvements in nutrient intakes, particularly for protein, fat quality, vitamin D and iron.

Protein intakes before simulation were twice as high as the RNI and at levels comparable to adults' diets in terms of percentage of energy. Whether this amount of protein has a long-term detrimental effect on health is still a matter of debate, although several studies have shown an association between protein-driven rapid weight gain in infancy and an increased risk of obesity in later life $[8,10,11]$. Therefore, the observed decrease in protein intake after simulation below the suggested UL for protein of $15 \% \mathrm{EI}$ [9] might be considered an improvement of the child's diet.

Total fat intake was decreased after simulating the replacement of cow's milk by YCF to a level below the recommended level, that is, $31 \% \mathrm{EI}$ compared to the recommended 35-40\%EI [18]. Nevertheless, the quality of fat intake improved in our simulation scenarios. SFA intake was decreased from $18 \% \mathrm{EI}$ to the recommended level of $11 \%$ EI [17]. Generally, SFA intakes are above the recom- 
mended level in young children living in Europe, for example in Finland [26] or the Netherlands [27], but intakes were particularly high in our sample. This is probably related to the selection of our sample to whole cow's milk users, in line with the dietary recommendation in the United Kingdom, but different from recommendation to drink either skimmed or semi-skimmed milk in Finland and the Netherlands, respectively. This may be an important nutritional reason to prefer (semi-)skimmed cow's milk over full-fat options.

Essential fatty acid intake increased in our simulation scenarios and its levels were brought more in line with the recommendation [2]. According to the EFSA NDA Panel, particular attention should be paid to ensure an appropriate supply of alpha-linolenic acid and docosahexaenoic acid in the diets of young children [5]. The DNSIYC does not contain any information on these specific fatty acids. Nevertheless, the observed increases in Cis $\mathrm{n} 3$ and Cis $\mathrm{n} 6$ fatty acids after simulation can be considered beneficial in that respect.

The increase in total sugar intake observed when replacing cow's milk by YCF at matching volume $(+12.9 \%)$ was mainly due to an increase in lactose $(73 \%$ of the increase). In our population, NMES represent $8.1 \%$ of EI at baseline. This increases to 9.0 and $9.6 \% \mathrm{EI}$ after replacing cow's milk intake by respectively, a matching volume or $300 \mathrm{ml}$ of YCF. These levels stay well within the recommended maximum limit of NMES intake of $11 \% \mathrm{EI}$ (online suppl. table). It is therefore not anticipated that the differences in NMES content between cow's milk and YCF impact long-term health. Nonetheless, some YCF marketed in and outside Europe, especially the flavoured options, contain high levels of NMES, such as sucrose, maltodextrin and glucose syrup [28]. The consumption of high levels of such easily absorbed sugars can stimulate excessive postprandial hypoglycaemia and insulinaemia, which may be linked to risks of obesity, type 2 diabetes and coronary heart disease [29]. Moreover, these sugars are likely to contribute to higher levels of dental decay in young children [30] and to a preference for sweet tastes later in life $[31,32]$. For this reason, YCF with the highest amount of lactose (as percentage of total carbohydrates) should be preferred.

Intake of vitamin $\mathrm{D}$ was very low at baseline in young children living in the United Kingdom and is likely to result in insufficient plasma levels of 25 -hydroxyvitamin D, especially during the winter months. This is consistent with the opinion of the EFSA Panel stating that total vitamin D supply originating from the diet and from endogenous synthesis is insufficient for most infants and young

Simulating Replacement of Cow's Milk by YCF children in Europe, depending on the season [5]. The UK recommendation on the use of vitamin D supplements is poorly followed, with only $10 \%$ of the children reporting a vitamin $\mathrm{D}$ supplement intake over the 4 days of the survey [4]. Therefore, fortified foods like YCF could be an effective way of increasing vitamin D intake.

Mean iron intakes of young children in the United Kingdom seem to be close to the RNI, that is, reaching $93 \%$ of the RNI of $6.9 \mathrm{mg} /$ day $[4,17]$. Nevertheless, still $13 \%$ of children had intakes below the LNRI [4], showing important variations in iron intake. In our population of whole cow's milk consumers, mean iron intakes before simulation were slightly lower, that is, at $5.2 \mathrm{mg} /$ day or $75 \%$ of the RNI and almost $20 \%$ of the subjects were not reaching the LNRI. The level of iron is similar in both whole and semi-skimmed cow's milk, that is, $0.03 \mathrm{mg} / 100$ $\mathrm{ml}$ in whole cow's milk and $0.02 \mathrm{mg} / 100 \mathrm{ml}$ in semiskimmed cow's milk [33]. This led us to the hypothesis that children who consume whole cow's milk may be less likely to consume iron-rich food, like meat, fruit and nuts, because of the relatively high energy contribution of the cow's milk in their diet [34].

Iodine levels in our sample were found to exceed the UL before simulation. Recent opinions from the EFSA Panel [35] and the Nordic recommendations [2] state that only a few data are available regarding the toxicity of iodine from excessive intakes. Although tolerance to high levels of iodine seems to be subject to a high level of interindividual variation, thyroid disorders have not been observed for intakes slightly above the UL. In contrast to the UK situation where iodine deficiency does not seem to be an issue, the EFSA NDA Panel recently reported that in a number of European countries, including Belgium, Germany and Spain, up to $24 \%$ of children had moderate iodine deficiency (urinary iodine concentration $<50$ $\mu \mathrm{g} / \mathrm{l})$ [5]. This discrepancy observed in iodine intakes and status at the European level may be explained by the iodine levels in cow's milk as stated in the different country-specific food composition databases ranging from $7 \mu \mathrm{g} / 100 \mathrm{~g}$ in the Netherlands [36] and $12 \mu \mathrm{g} / 100 \mathrm{~g}$ in Germany [37] to $31 \mu \mathrm{g} / 100 \mathrm{~g}$ in the United Kingdom [33].

Intake levels of calcium and sodium were similar before and after simulation (Scenario 1). For calcium, this can be easily explained by the fact that the calcium level of the YCF that we used in this study was equal to the level found in whole cow's milk. When the volume of milk intake was decreased in Scenario 2, calcium intake levels likewise decreased to an average level still above the UK RNI for calcium. For sodium, despite the fact that YCF has a lower level compared to whole cow's milk, that is, 
$26 \mathrm{mg} / 100 \mathrm{ml}$ compared to $43 \mathrm{mg} / 100 \mathrm{ml} \mathrm{[33],} \mathrm{sodium}$ intake levels were not drastically reduced in our simulation scenarios. This implies that cow's milk is not the main driver of sodium intake in a young child's diet and that other sources like processed foods targeting adults may be the main contributors of sodium intake. This is an argument in favour of approaches that target the diet as a whole in trying to reach nutrient recommendations.

For both retinol and zinc, the percentage of children exceeding the UL increased after the replacement of cow's milk with YCF. The increase for retinol was very small, that is, from $1 \%$ of children exceeding the UL before simulation to 3\% in Scenario 1. Nevertheless, based on the p95 for retinol intakes, consumption of YCF over $650 \mathrm{ml} /$ day could result in intakes exceeding the UL. In this regard, our simulation suggests that attention should be paid to the high consumers of YCF, as well as to the vitamin A content in the recipes of such products. Mean intakes of zinc were slightly above the UL when cow's milk was replaced by YCF at a matching volume. A total of 55 and $15 \%$ of children had intakes exceeding the UL in Scenario 1 and Scenario 2, respectively, compared to $6 \%$ before simulation. Results from several dietary surveys conducted in Europe [27, 38] suggest that P95 intakes of zinc are generally high and exceed the UL. No adverse health effects have been associated with these intake levels in the population and this made the Scientific Committee of Food to conclude that zinc intakes close or above the UL are not a matter of concern [22]. Moreover, while the UL set by the Scientific Committee of Food and used for this study is $7 \mathrm{mg} /$ day, the World Health Organization set an UL of 23-28 mg/day for zinc for children [39].

With the exception of vitamin D, the YCF that we have used in the simulation scenarios is comparable to other YCF recipes marketed in European countries (i.e. nutrient value close to the median of recipes on the EU market; table 1). Therefore, for a vast majority of macro- and micronutrients, the results are generalizable to other YCF recipes in Europe. For vitamin D, the YCF that we have used in our analysis has higher levels compared to the p95 of recipes in the EU and analyses have to be repeated to gain representative results for this specific vitamin.

\section{Limitations}

This study has some limitations that should be considered when interpreting the results. First, we restricted our population to children with a milk consumption made up exclusively of whole cow's milk, because whole cow's milk is the recommended choice of milk for the sample's age range $[14,15]$. Indeed, the DNSIYC shows that $79 \%$ of the children aged 12-18 months consumed whole cow's milk over the survey period [4]. Therefore, the results from this study apply only to consumers of whole cow's milk and they cannot be extended to the total population. Further research is warranted to test more complex simulation scenarios taking into account the diversity of observed consumption patterns (e.g. the combination of different types of milks and YCF). Other statistical simulation models could also be used in order to analyse consumption not just based on 4 days of consumption records, but instead to deduce usual nutrient intakes from these records, which better reflect real consumption patterns. Second, in this study, we simulated changes in dietary intake and it is not clear how feasible it would be for our sample to apply such dietary changes in a real-life setting. Yet, the consumption of YCF, a milk-based fortified drink, instead of cow's milk only requires the replacement of one food item by a similar one and would therefore not drastically change dietary habits. The type of food, usage and the moment of consumption can be considered unchanged. However, possible interactions between milk and other foods were not taken into account. Moreover, the cost of YCF compared to cow's milk could be another limiting factor for parents to buy such products. Advanced diet-modelling techniques would allow us to take into account both cost and nutritional parameters in order to design a nutritionally adequate and socially acceptable diet $[40,41]$. Lastly, the decrease in milk intake in Scenario 2 was not compensated by increased energy intake from other food items, leading to a decrease in the total daily energy intake of approximately $410 \mathrm{~kJ}$ (or $100 \mathrm{kcal}$ ). Nevertheless, this scenario confirmed that the on-pack recommendation of $300 \mathrm{ml}$ is sufficient to bring nutrient intakes in line with the recommendations. The daily intake of $300 \mathrm{ml}$ of YCF is in line with the food recommendation published by the British Nutrition Society [16] and the UK Infant and Toddler Forum [14], who recommends three portions of dairy products per day for children 12-18 months, with a portion of milk being $100 \mathrm{ml}$. Also other authors have recommended a maximum of $400 \mathrm{ml}$ milk products per day, as consuming a higher volume of milk is accompanied by less consumption of other nutrient-rich complementary foods [34, 42].

\section{Conclusion}

This simulation study suggests that replacing cow's milk by YCF may help to bring nutrient intakes more in line with the recommendations. The use of YCF could 
be one way to increase specific nutrients (e.g. vitamin D, iron) that are often lacking in the diets of young children. The manufacturer's recommendation of a daily intake of $300 \mathrm{ml}$ appears to be an appropriately sized daily intake to increase the level of specific micronutrients such as vitamin $\mathrm{D}$, iron and essential fatty acids, while further contributing to a decrease in other nutrients, such as SFA and protein. Study data are needed to confirm that the assumptions and conclusions drawn in this theoretical simulation study are applicable in real life too.

\section{Acknowledgements}

The DNSIYC is funded by the UK Department of Health and made available to researchers under license via the UK Data Archive.

The authors thank Danone Food Safety Center for its opinions on food safety issues, as well as Clare Llewellyn and Hayley Syrad (King's College London) for their critical evaluation of the manuscript.

\section{Disclosure Statement}

All authors are employees of Danone Nutricia Research.

\section{References}

1 World Health Organization: The WHO Child Growth Standards. http://www.who.int/ childgrowth/standards/en/ (accessed June 26, 2012).

2 Nordic Council of Ministers: Nordic Nutrition Recommendations 2012. Integrating $\mathrm{Nu}$ trition and Physical Activity. 2012. www. norden.org (accessed February 10, 2015).

3 Dovey TM, Staples PA, Gibson EL, Halford JC: Food neophobia and 'picky/fussy' eating in children: a review. Appetite 2008;50:181193.

4 Lennox A, Sommerville J, Ong K, Henderson $\mathrm{H}$, Allen R: Diet and Nutrition Survey of Infants and Young Children, 2011. A survey carried out on behalf of the Department of Health and Food Standards Agency. London, Department of Health, 2013.

5 EFSA Panel on Dietetic Products Nutrition and Allergies (NDA): Scientific Opinion on nutrient requirements and dietary intakes of infants and young children in the European Union. EFSA J 2013;11:3408.

6 Gibson S, Sidnell A: Nutrient adequacy and imbalance among young children aged 1-3 years in the UK. Nutrition Bulletin 2014; 39:172-180.

7 EFSA Panel on Dietetic Products Nutrition and Allergies (NDA): Scientific opinion on the essential composition of infant and follow-on formulae. EFSA J 2014;12:3760.

8 Koletzko B, Brands B, Poston L, Godfrey K, Demmelmair H: Early nutrition programming of long-term health. Proc Nutr Soc 2012;71:371-378.

9 Agostoni C, Scaglioni S, Ghisleni D, Verduci E, Giovannini M, Riva E: How much protein is safe? Int J Obes (Lond) 2005;29(suppl 2):S8-S13.

10 Hörnell A, Lagström H, Lande B, Thorsdottir I: Protein intake from 0 to 18 years of age and its relation to health: a systematic literature review for the 5th Nordic nutrition recommendations. Food Nutr Res 2013:57.

11 Michaelsen KF, Greer FR: Protein needs early in life and long-term health. Am J Clin Nutr 2014;99:718S-722S.
12 Kloosterman J, Fransen HP, de Stoppelaar J, Verhagen H, Rompelberg C: Safe addition of vitamins and minerals to foods: setting maximum levels for fortification in the Netherlands. Eur J Nutri 2007;46:220-229.

13 Smithers G: MAFF's nutrient databank. Nutr Food Sci 1993;2:16-19.

14 Infant \& Toddler Forum: Portion Sizes for Children Aged 1-4 years. http://www.infant andtoddlerforum.org/portion-sizes-table (accessed June 17, 2015).

15 British Nutrition Foundation: Healthy Eating: Milk and Dairy Foods 2014. http://www. nutrition.org.uk/attachments/article/721/ Milk\%20and\%20dairy\%20foods.pdf (accessed June 17, 2015).

16 British Nutrition Foundation: 5532-A-Day 2014. http://www.nutrition.org.uk/attach ments/article/734/BNF\%20Toddler\%20Eat well\%20Poster_OL.pdf (accessed June 17, 2015).

17 Department of Health: Dietary Reference Values for Food Energy and Nutrients for the United Kingdom. Report on Health and Social Subjects. London, HMSO, 1991.

18 EFSA Panel on Dietetic Products Nutrition and Allergies (NDA): Scientific opinion on dietary reference values for fats, including saturated fatty acids, polyunsaturated fatty acids, monounsaturated fatty acids, trans fatty acids, and cholesterol. EFSA J 2010;8:1461.

19 EFSA Panel on Dietetic Products Nutrition and Allergies (NDA): Scientific opinion on dietary reference values for carbohydrates and dietary fibre. EFSA J 2010:8.

20 EFSA Panel on Dietetic Products Nutrition and Allergies (NDA): Scientific opinion on dietary reference values for protein. EFSA J 2012;10:2557.

21 Vinas BR, Barba LR, Ngo J, Gurinovic M, Novakovic R, Cavelaars A, et al: Projected prevalence of inadequate nutrient intakes in Europe. Ann Nutr Metab 2011;59:84-95.

22 EFSA Scientific Committee on Food: Scientific Panel on Dietetic Products Nutrition and Allergies. Tolerable Upper Intake Levels for Vitamins and Minerals. 2006.
23 Institute of Medicine; Food and Nutrition Board; Panel on Dietary Reference Intakes for Electrolytes and Water; Standing Committee on the Scientific Evaluation of Dietary Reference Intakes: Dietary Reference Intakes for Water, Potassium, Sodium, Chloride, and Sulfate. Washington, The National Academies Press, 2005.

24 Walton J, Flynn A: Nutritional adequacy of diets containing growing up milks or unfortified cow's milk in Irish children (aged 12-24 months). Food Nutr Res 2013:57.

25 Ghisolfi J, Fantino M, Turck D, de Courcy GP, Vidailhet M: Nutrient intakes of children aged 1-2 years as a function of milk consumption, cows' milk or growing-up milk. Public Health Nutr 2013;16:524-534.

26 Kyttälä P, Erkkola M, Kronberg-Kippilä C, Tapanainen H, Veijola R, Simell O, et al: Food consumption and nutrient intake in Finnish 1-6-year-old children. Public Health Nutr 2010;13:947-956.

27 Ocké MC, Van Rossum CTM, Fransen HP, Buurma EM, De Boer EJ, Brants HAM, et al: Dutch National Food Consumption Survey Young Children, 2005/2006.

28 Crawley H, Westland S: Fortified milks for children. A worldwide review of fortified milks marketed for children over 1 year of age. Wordworks, First Steps Nutrition Trust, 2013.

29 Brand-Miller J, Atkinson F, Rowan A: Effect of added carbohydrates on glycemic and insulin responses to children's milk products. $\mathrm{Nu}$ trients 2013;5:23-31.

30 Grenby TH, Mistry M: Properties of maltodextrins and glucose syrups in experiments in vitro and in the diets of laboratory animals, relating to dental health. Br J Nutr 2000;84: 565-574.

31 Liem DG, Mennella JA: Sweet and sour preferences during childhood: role of early experiences. Dev Psychobiol 2002;41:388-395.

32 Mennella JA, Beauchamp GK: Flavor experiences during formula feeding are related to preferences during childhood. Early Hum Dev 2002;68:71-82. 
33 Food Standards Agency, McCance and Widdowson: The Composition of Food. 2002. http://tna.europarchive.org/20110116113217/ http://www.food.gov.uk/science/dietarysur veys/dietsurveys/ (accessed February 18, 2015).

34 Thane CW, Walmsley CM, Bates CJ, Prentice A, Cole TJ: Risk factors for poor iron status in British toddlers: further analysis of data from the national diet and nutrition survey of children aged 1.5-4.5 years. Public Health Nutr 2000;3:433-440.

35 EFSA Panel on Dietetic Products Nutrition and Allergies (NDA): Scientific opinion on dietary reference values for iodine. EFSA J 2014; $12: 3660$.
36 National Institute for Public Health and the Environment (RIVM): Dutch Food Composition Database. 2013. http://www.rivm.nl/ en/Topics/D/Dutch_Food_Composition Database (accessed February 18, 2015).

37 Köhler M, Fechner A, Leiterer M, Spörl K, Remer T, Schäfer U, et al: Iodine content in milk from German cows and in human milk: new monitoring study. Trace Elem Electrolytes 2012;29:119-126

38 Kyttala P, Erkkola M, Kronberg-Kippila C, Tapanainen H, Veijola R, Simell O, et al: Food consumption and nutrient intake in Finnish 1-6-year-old children. Public Health Nutr 2010;13:947-956.

39 Joint FAO/WHO Expert Consultation on Human Vitamin and Mineral Requirements: Vitamin and Mineral Requirements in Human Nutrition, ed 2. Geneva, 2004.
40 Darmon N, Ferguson EL, Briend A: A cost constraint alone has adverse effects on food selection and nutrient density: an analysis of human diets by linear programming. J Nutr 2002;132:3764-3771.

41 Briend A, Darmon N, Ferguson E, Erhardt JG: Linear programming: a mathematical tool for analyzing and optimizing children's diets during the complementary feeding period. J Pediatr Gastroenterol Nutr 2003;36:12-22.

42 Uijterschout L, Vloemans J, Vos R, Teunisse PP, Hudig C, Bubbers S, et al: Prevalence and risk factors of iron deficiency in healthy young children in the southwestern Netherlands. J Pediatr Gastroenterol Nutr 2014;58:195-200. 